\title{
DESIGN OF MOORING FITTINGS OF SHIP EPQIPMENT BY USING THE FINITE ELEMENT METHOD
}

\author{
Jung-Yong Han ${ }^{1}$ and Byung-Young Moon ${ }^{2 *}$ \\ ${ }^{1}$ Department of Mechanical Engineering, Pusan National University, Pusan, Korea \\ ${ }^{2}$ Department of Naval Architecture, Kunsan National University, Kunsan, Korea \\ * Corresponding author (moonby20@gmail.com)
}

\begin{abstract}
Mooring and Towing Fittings mean various devices and fittings to safely fasten vessels to quays, jetties, seafloating buoys. etc. They include devices such as mooing winches and capstans, fitting such as chocks, fairleads, guide rollers, bollards, and bitts, and the seats and reinforced parts of vessels such fittings are installed. They also include ropes and chains used for mooring and chain stoppers that secure chains to vessels. Because of damage to mooring fittings during mooring directly related to large-scale accidents such as the drifting of vessels, mooring fittings with strength appropriate for the physical features of the vessels must be installed. The reinforcement of the vessels on which the mooring fittings are installed must be designed to withstand the loads transferred from the fittings as well. Also Mooring fittings with efficient strength are required because damaged ships lead to sea pollution such as oil or fuel oil spillage. The purpose of this study is to suggest the standardization model for strength analysis of the closed chocks by using the Finite Elements Method and Equipment Test.
\end{abstract}

Keywords: Design Of Ship Equipment System, Structural Safety, Fitting Device, Design of Mooring System, Chock, Standardization Model, Equipment Test, Safety Working Load

\section{INTRODUCTION}

As background of research, mooring and towing fittings mean all equipment used for fastening ships to quays, piers, and buoys from the tide, wind load, and wave load safely. These mooring and towing fittings are the requisite structure established on all the ships regardless of their kinds. They are made up of tools such as mooring winch, fittings such as chock, fairlead, guide roller, bollard and bitt, seat on which fittings are installed and reinforced parts of the ship. They also cover rope used in mooring, a chain and a chain stopper used to fasten the chain to a ship. They are required to be installed with strength appropriate for the size of the ship and the reinforcement of ship's lower part must be designed strongly enough to endure load transmitted from mooring and towing fittings. In case of using mooring and towing fittings whose strength is unproved, large-scale accidents and sea pollution by the spill of cargo and fuel oil from the wrecked ships could be caused. So enough strength is especially required. Nevertheless, the standards of selecting and applying mooring and towing fittings haven't ever existed or are different one another. It could be a very vast work to verify the design and strength according to all the types and sizes of mooring fittings because their types are various and they must be applied differently to various sizes of ships. Currently, the standards of design about mooring fittings are different among national shipyards and different standards are being applied to the same item. For this reason, the necessity for standardization of mooring and towing fittings was brought up. So four domestic shipyards Daewoo, Samsung, Hanjin, and Hyundai have made up a committee since 2003, and have laid the foundation for standardization of mooring fittings applied to tank-ships over 5 years. Henceforth, with continuous research of strength analysis for mooring and towing fittings, Junmo Jeong developed an automation program for application of rope loads of various mooring fittings using MSC. Patran a 
commonly used FEM program, and Sanrae Jo carried out the nonlinear strength analysis for Volard-type mooring fittings. Recently as part of business for improving standard technical skills of the Korea Agency for Technology and Standards in the Ministry of Knowledge Economy, some national big shipyards have made a committee and conducted standardization for mooring fittings under Shipbuilding Equipment Institute. The research subject is a closed chock which is being most used of mooring and towing fittings. The closed chocks are divided into two types; one is a seat type including seat which is a structure supporting the chock rope passes through, and the other is a bulwark type including bulwark which surrounds the chock. Chocks are mostly made of cast steel, and seat and bulwark are made by processing steel sheet. Most components must satisfy the regulation of OCIMF(Oil Companies International Maine Forum). The committee of mooring and towing fittings selected 10 types of standardization object according to each different size. And the objective of this study is to prove the suitability of standardization object by performing strength analysis for total 20 types. And also an actual strength test for one type would be done to examine the relation with the analysis value of strength. The final objective of this study is to perform the strength analysis for closed chocks which are most commonly used of all mooring and towing fittings with FEM, and to standardize it. Closed chocks could be divided into the seat type and the bulwark type and FE analysis for total 20 closed chocks by each type was performed to prove the suitability of standardization objects.

\section{STRENGTH EVLAUATION TEST MODEL}

In this research, the analysis for 20 types of closed chocks which are most used of all sorts of mooring and towing fittings was made, and strength test on the Panama chock which is a special type of closed chocks was also done to verify analysis value. The closed chocks could be divided into the seat type and the bulwark type and FE analysis for total 20 closed chocks by each type was performed to prove the suitability of standardization objects. Drawings of 10 types of closed chocks for seat type were presented in Fig. 1.
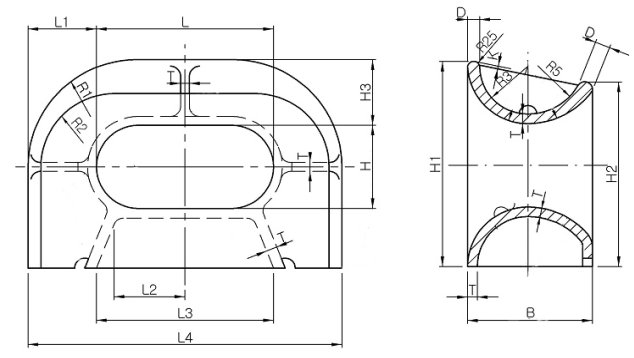

(a) Drawing of closed chocks for seat type

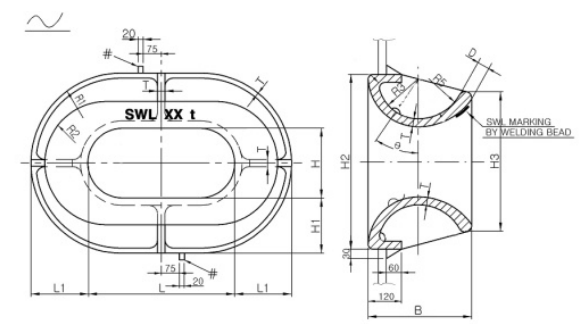

(b) Drawing of closed chocks for bulwark type Drawing of closed chocks type

The closed chocks applied SCW480 in consideration of the strength of material and weld-ability. Seats applied $\mathrm{SS} 400(\mathrm{C}<=0.23 \%)$. Material properties were presented in Table 1. As an analysis method, target Safety Working Load for each size was presented in Table 6, and the analysis was made with setting it as the standard of comparing with the results of analysis. Load conditions were analyzed with the condition 1(LC1) and 2(LC2) among the cases in which rope works like Fig 2. For the case of load condition 1, regarding the load in the case that rope is bent to $180^{\circ}$ through $\operatorname{chock}\left(\theta=20^{\circ}\right)$ and $\mathrm{P}$ means mooring or towing load given to the rope. For the case of load condition 2, regarding the load in the case that rope is bent to downward $90^{\circ}$ outside of the vessel, downward $30^{\circ}$ in the vessel. Then tension $(\mathrm{P})$ given to the rope is applied to the chock.

Table 1 Material properties for closed choc

\begin{tabular}{|l|l|l|l|l|}
\hline \multicolumn{1}{|c|}{ Type } & $\begin{array}{c}\text { Elastic Modulus } \\
{[\text { GPa] }}\end{array}$ & $\begin{array}{c}\text { Poisson } \\
\text { Ratio }\end{array}$ & $\begin{array}{c}\text { Yield Stress } \\
\text { [MPa] }\end{array}$ & Rernarks \\
\hline SCW 480 & 206 & 0.3 & 275 & Casting \\
\hline SS400 & 206 & 0.3 & 235 & Steel P late \\
\hline
\end{tabular}


Table 2 Target SWL for each size

\begin{tabular}{|c|c|c|}
\hline No. & Nominal Size & $\begin{array}{c}\text { Target } \\
\text { SWL }\end{array}$ \\
\hline 1 & $310 * 260 * 358$ & 46 \\
\hline 2 & $360 * 260 * 358$ & 68 \\
\hline 3 & $400 * 250 * 358$ & 70 \\
\hline 4 & $450 * 250 * 358$ & 70 \\
\hline 5 & $500 * 250 * 358$ & 70 \\
\hline 6 & $400 * 250 * 428$ & 86 \\
\hline 7 & $450 * 250 * 428$ & 86 \\
\hline 8 & $500 * 250 * 428$ & 86 \\
\hline 9 & $500 * 400 * 428$ & 86 \\
\hline 10 & $500 * 400 * 525$ & 115 \\
\hline
\end{tabular}

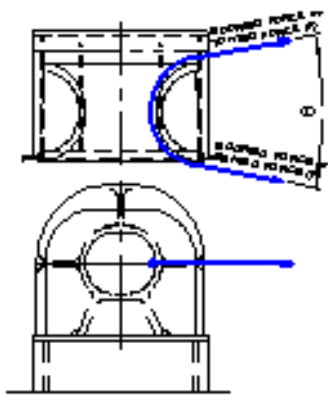

(a) Load case1 (LC1)

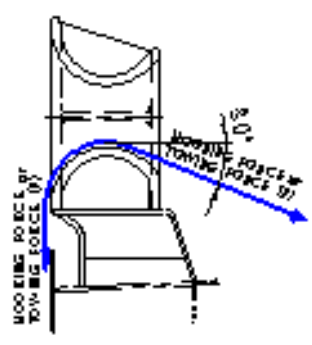

(b) Load case2 (LC2)
Fig. 2 Boundary conditions for each load case (LC1, LC2)

Safely used load was calculated by allowable stress and calculated stress. Here, the allowable stress $=$ yield stress $\mathrm{x}$ 1.06, design load $=1.25 \mathrm{x}$ SWL are applied. But the load applied to analysis must be design $\operatorname{load}(=1.25 \mathrm{x} \mathrm{P})$. This means that calculated stress was not allowed to be over the $85 \%$ of yield stress of material(=1.06/1.25). Unit load 1 $\mathrm{N}$ was applied to the rope, and the strength transmitted to the chock by the rope was applied with the value taken by calculating direct load. Only the values of coordinate of node in FE model are given, the power inflicted to node can be calculated by vector calculus. In the case of load condition 1, load applied to FE model was presented in Fig. 3. Boundary conditions for displacement were presented in Fig. 4. Marks in Fig. 4 were fixed with Dx, Dy, Dz displacements for $\mathrm{X}, \mathrm{Y}, \mathrm{Z}$ coordinates and rotation coordinates $\mathrm{Rx}, \mathrm{Ry}, \mathrm{Rz}$.
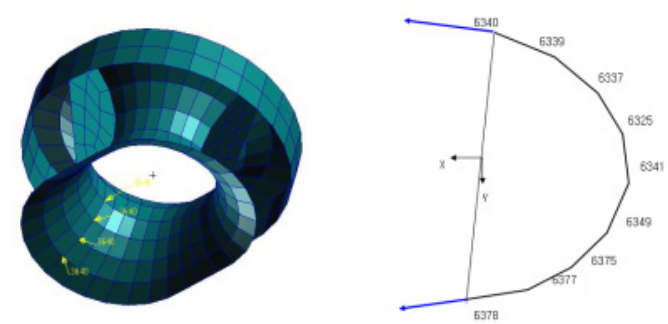

Fig. 3 Applied load condition
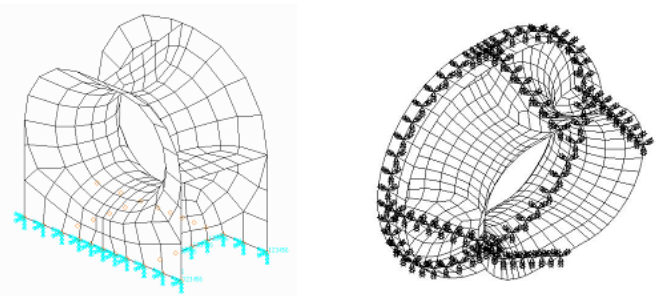

Fig. 4 Boundary condition for displacement

\section{Experiment of strength evaluation for closed chocks} For one case of 20 types of standardization model for closed chocks, strength test was made to verify the results of FE analysis. The name of closed chocks including number $1,2(310 * 260 * 358,360 * 260 * 358)$ of 10 sizes like Table 3 were called Panama chock and Panama chock is a special chock used during the passage of Panama channel. Test case is seat type for Panama chock and Equipment for test was presented in Fig. 5. With an end of rope fixed and towing load from 0 ton to 205 ton inflicted at the other end, the test was conducted as shown in Fig. 5. By increasing load gradually and setting strain gauge in each part of chock and seat, the transformed amount was calculated.

Table 3 Sizes for closed chock and test case

\begin{tabular}{|c|c|c|}
\hline No. & Nominal size & Remark \\
\hline 1 & $310 * 260 * 358$ & Panama chock \\
\hline 2 & $360 * 260 * 358$ & Panama chock (test case) \\
\hline 3 & $400 * 250 * 381$ & Closed chock \\
\hline 4 & $450 * 250 * 381$ & Closed chock \\
\hline 5 & $500 * 250 * 381$ & Closed chock \\
\hline 6 & $400 * 250 * 428$ & Closed chock \\
\hline 7 & $450 * 250 * 428$ & Closed chock \\
\hline 8 & $500 * 250 * 428$ & Closed chock \\
\hline 9 & $500 * 400 * 428$ & Closed chock \\
\hline 10 & $500 * 400 * 525$ & Closed chock \\
\hline
\end{tabular}




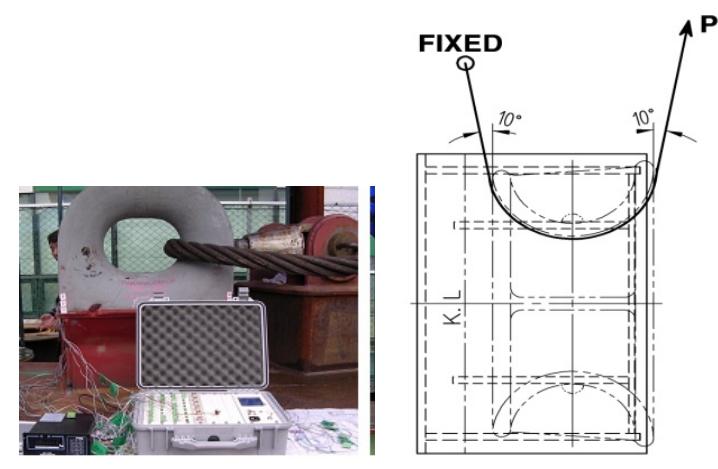

Fig. 5 Equipment for test and application of tensile load

\section{Results and Discussions of experiment and analysis}

\subsection{Strength Test evaluation and results of FE analysis}

As the results of strength evaluation test, towing load and stress obtained from monitoring system of test equipment on the measurement location of Panama chock \& seat were presented in Table 4 and Fig. 6 . When towing yield stress of seat or bulwark material amounted to $235 \mathrm{MPa}$, the value of towing load was calculated as about 95 ton.

Table 7 Nodal coordinates and forces for Load Case 1 (Nominal Size

$360 * 260 * 358)$
\begin{tabular}{|c|c|c|c|c|}
\hline Node & $\mathrm{X}$ & $\mathrm{Y}$ & $\mathrm{Z}$ & $\mathrm{F}$ \\
\hline 6340 & 0.102679 & 0.303539 & 0 & 0.320435 \\
\hline 6339 & 0.296966 & 0.30753 & 0 & 0.427508 \\
\hline 6337 & 0.262382 & 0.143121 & 0 & 0.298878 \\
\hline 6325 & 0.261218 & 0.060577 & 0 & 0.26815 \\
\hline 6341 & 0.301804 & -0.01454 & 0 & 0.302154 \\
\hline 6549 & 0.342321 & -0.08966 & 0 & 0.353869 \\
\hline 6375 & 0.208547 & -0.14822 & 0 & 0.255852 \\
\hline 6377 & 0.338734 & -0.40694 & 0 & 0.529472 \\
\hline 6378 & 0.018438 & -0.13453 & 0 & 0.135788 \\
\hline
\end{tabular}

\subsection{FE analysis Results of Panama chock}

Calculation of SWL for design of allowable stress is carried out. Allowable stress at SWL for Panama chock \& seat was presented Table 5. Allowable stress was set up as 1.06 times more than yield stress. Accordingly, allowable stress of chock was set into $291.5 \mathrm{MPa}$, and that of seat was $249.1 \mathrm{Mpa}$. When Unit load $1 \mathrm{~N}$ is applied, outcome value of stress analysis is as same as that of allowable stress when real load(ton) is inflicted. Results of FE analysis for chock only(Alt. 1) were presented in Table 6 and Fig. 7 and those of FE analysis including both chock and seat(Alt. 2) were Table 7 and Fig. 8.

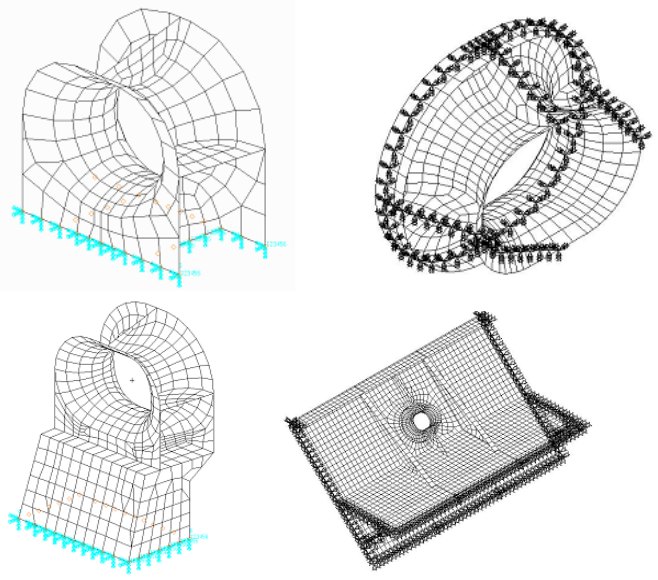

Fig. 9 Boundary condition for displacement

In the case of analysis for chock only, maximum stress obtained from FE analysis was 2.62E-4 MPa, and SWL was obtained. It could be a permissible level because it was larger than target SWL 68 ton.

Table 4 Results of test for Panama chock \& seat

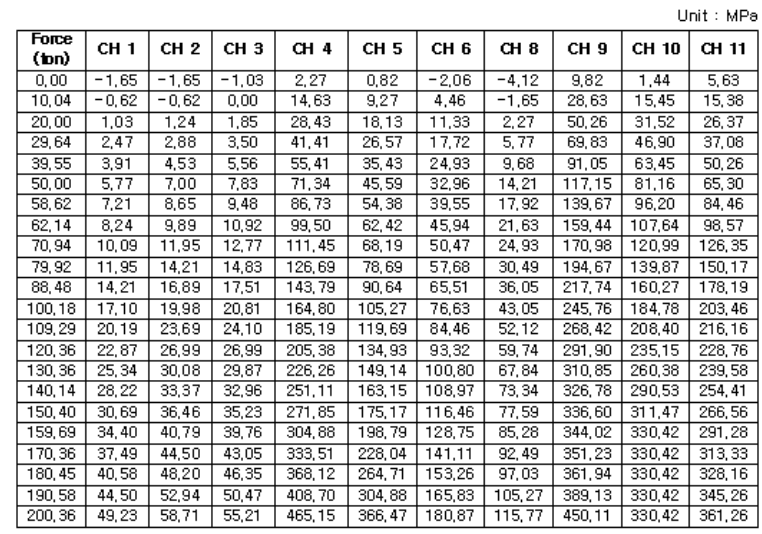

In the case of analysis for both chock and seat, maximum stress of chock was 2.84E-4 MPa, and seat was 3.11E-4 MPa. SWL calculated from the same method were 73.44 ton and 70.36 ton respectively. They were also permissible level because they were larger than target SWL 68 ton. In the strength test for Panama chock, towing load was calculated as 95 ton and result of FE analysis was 70.36 ton. 


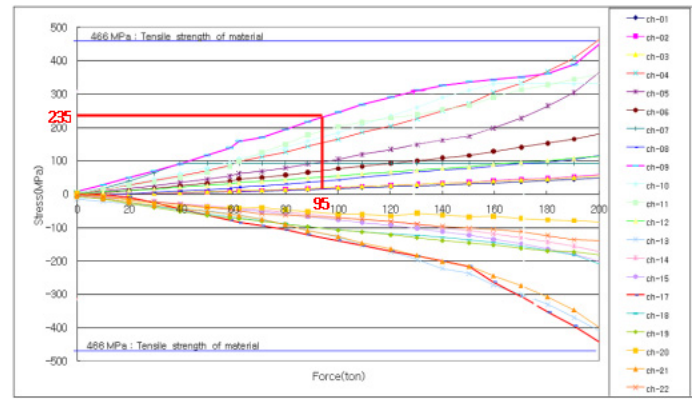

Fig. 6 Force[ton] - Stress[MPa] curves of Panama chock \& seat

Table 5 Allowable stress at SWL

\begin{tabular}{|c|c|c|}
\hline Application & Chock & Seat \\
\hline $\begin{array}{c}\text { Allowable stress } \\
\text { at SWL }\end{array}$ & $\begin{array}{c}1.06 \text { times of Yield } \\
(291.5 \mathrm{MPa})\end{array}$ & $\begin{array}{c}1.06 \text { times of Yield } \\
(249.1 \mathrm{MPa})\end{array}$ \\
\hline Material & SCW 480 & SS400 \\
\hline Yield Stress[MPa] & 275 & 235 \\
\hline
\end{tabular}

Table 6 Result of FE analysis for chock only

\begin{tabular}{|c|c|c|c|}
\hline $\begin{array}{c}\text { Load } \\
\text { Condition }\end{array}$ & $\begin{array}{c}\text { Von-Mises Stress } \\
(\mathrm{E}-\mathbf{4} \text { MP a) }\end{array}$ & SWL(ton) & \multirow{2}{*}{$\begin{array}{c}\text { Target } \\
\text { SWL }\end{array}$} \\
\cline { 2 - 3 } & Chock & Chock & \\
\hline LC1 & 2.90 & 82.05 & 68 \\
\hline
\end{tabular}

The outcome of strength test 95 ton was 1.15 times bigger than real numerical value 82.78 ton. When considering all the facts from strength test and result of FE analysis, yield stress of chock was regarded as rational when shown in the respect of design. To take outcome of analysis 70.36 ton into account with design load 1.25 and allowable stress 1.06, real value obtained from analysis without consideration of safety factor could be 82.78 ton. As a result strength analysis of Panama chock, a special type of closed chock applying during passage through Panama channel was conducted making use of FEM and its result was verified through actual strength test. The results of FEM and test were comparatively coincided showing about 15 percent error.

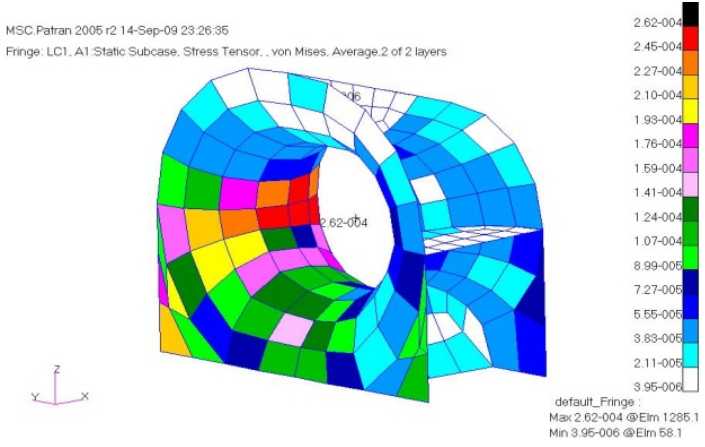

Fig. 7 Results of FE analysis for Alt.1 at Panama chock

Table 7 Result of FE analysis for one chock and single seat

\begin{tabular}{|c|c|c|c|c|c|}
\hline \multirow{2}{*}{$\begin{array}{c}\text { Load } \\
\text { Condition }\end{array}$} & \multicolumn{2}{|c|}{$\begin{array}{c}\text { Von-Mises Stress } \\
\text { (E-4 MPa) }\end{array}$} & \multicolumn{2}{c|}{ SW L(ton) } & \multirow{2}{*}{$\begin{array}{c}\text { Target } \\
\text { SWL }\end{array}$} \\
\cline { 2 - 5 } & Chock & Seat & Chock & Seat & \\
\hline LC1 & 3.24 & 2.89 & 73.44 & 70.36 & 68 \\
\hline
\end{tabular}

Fig. 8 Results of FE analysis for Alt.2 at Panama chock

\subsection{Standardization strength analysis of closed chock}

Seat type analysis was conducted into 3 cases separately as shown in Table 8 . Analysis results according to standard by using FEM method for seat type of closed chock was presented in Table 9. As shown in Tables, in three cases, all 10 types obtained outcome value exceeding target SWL.

Table 8 Analysis conditions for seat type

\begin{tabular}{|l|l|}
\hline Alt. & \multicolumn{1}{|c|}{ Analysis condition } \\
\hline Alt. 1 & Chock only \\
\hline Alt. 2 & Chock + Single seat \\
\hline Alt. 3 & Chock + Double seat \\
\hline
\end{tabular}

Application of SWL according to allowable stress design was considered as proper and FE analysis for closed chocks with various sizes was conducted on the basis of these analysis results, performing verification of the structure analysis for standardization objects. 
Table 9 Results of FE analysis for chock only

\begin{tabular}{|c|c|c|c|c|}
\hline \multirow[t]{2}{*}{ Norninal size } & \multirow[t]{2}{*}{$\begin{array}{c}\text { Load } \\
\text { condition }\end{array}$} & $\begin{array}{c}\text { Von-Mises } \\
\text { stress } \\
\text { (E-4 MPa) }\end{array}$ & SWL(ton) & \multirow[t]{2}{*}{$\begin{array}{c}\text { Target } \\
\text { SWL } \\
\text { (ton) }\end{array}$} \\
\hline & & Chock & Chock & \\
\hline \multirow{2}{*}{$310 * 260 * 358$} & LC1 & 3.19 & 74.52 & \multirow{2}{*}{46} \\
\hline & LC2 & 3.25 & 73.14 & \\
\hline \multirow{2}{*}{$360 * 260 * 358$} & LC1 & 2.90 & 82.05 & \multirow{2}{*}{68} \\
\hline & LC2 & 2.36 & 100.73 & \\
\hline \multirow{2}{*}{$400 * 250 * 381$} & LC1 & 3.10 & 76.68 & \multirow{2}{*}{70} \\
\hline & LC2 & 2.17 & 109.55 & \\
\hline \multirow{2}{*}{$450 * 250 * 381$} & LC1 & 2.81 & 84.60 & \multirow{2}{*}{70} \\
\hline & LC2 & 2.05 & 115.96 & \\
\hline \multirow{2}{*}{$500 * 250 * 381$} & LC1 & 2.69 & 88.37 & \multirow{2}{*}{70} \\
\hline & LC2 & 2.21 & 107.56 & \\
\hline \multirow{2}{*}{$400 * 250 * 428$} & LC1 & 2.26 & 105.18 & \multirow{2}{*}{86} \\
\hline & LC2 & 2.43 & 97.83 & \\
\hline \multirow{2}{*}{$450 * 250 * 428$} & LC1 & 2.28 & 104.26 & \multirow{2}{*}{86} \\
\hline & LC2 & 2.19 & 108.55 & \\
\hline \multirow{2}{*}{$500 * 250 * 428$} & LC1 & 2.26 & 105.18 & \multirow{2}{*}{86} \\
\hline & LC2 & 2.01 & 118.27 & \\
\hline \multirow{2}{*}{$500 * 400 * 428$} & LC1 & 2.24 & 106.12 & \multirow{2}{*}{86} \\
\hline & LC2 & 2.00 & 118.86 & \\
\hline \multirow{2}{*}{$500 * 400 * 525$} & LC1 & 1.71 & 139.02 & \multirow{2}{*}{115} \\
\hline & LC2 & 1.59 & 149.51 & \\
\hline
\end{tabular}

From these results, basic work on such things as prevention of oil spillage by drift of ships and damage of the hull, and check for large-scale accidents, offering each large or small shipyard the standard through standardization work of closed chocks are considered and verified.

\section{Conclusions}

This research conducted standardization of closed chocks used most generally of mooring and towing fittings by making strength analysis through FEM. The conclusion from this research is as follows. First, strength analysis of Panama chock, a special type of closed chock applying during passage through Panama channel was conducted making use of FEM and its result was verified through actual strength test. The results of FEM and test were comparatively coincided showing about 15 percent error.

Application of SWL according to allowable stress design was considered as proper and FE analysis for closed chocks with various sizes was conducted on the basis of these analysis results, performing verification of the structure analysis for standardization objects. This research presented basic work on such things as prevention of oil spillage by drift of ships and damage of the hull, and check for large-scale accidents, offering each large or small shipyard the standard through standardization work of closed chocks.

\section{References}

[1] Park, In-Kyu ; Kim, Kyong-Moo, “Conceptual Design of Deep-sea Multi-Point Mooring by using Two-Point Mooring", Journal of the Society of Naval Architects of Korea, Volume 45, Issue , August 2008, pp.462-467

[2] Lim, Choon-Gyu ; Lee, Ho-Young ; Shin, HyungYoung , "Nonlinear Motion Analysis of FPSO and Shuttle Tanker in a Tandem Configuration", Journal of the Society of Naval Architects of Korea, Volume 43, Issue , October 2006, pp.560-567

[3] Lim, Yu-Chang, Kim, Kyung-Su, Choung, Joon-Mo , "Fatigue Damage Combination for Spread Mooring System under Stationary Random Process with Bimodal Spectrum Characteristics" Journal of the Society of Naval Architects of Korea, Volume 47, Issue, December 2010, pp.813-820

[4] Oh, Chang-Min ; Choung, Joon-Mo ; Cho, Sang-Rai , "Ultimate Strength Assessment of Bollard and Its Foundation Considering Production Costs", Journal of the Society of Naval Architects of Korea, Volume 43, Issue 5, October 2006, pp 604-610

[5] Mooring Fitting SWL Standardization(Dry Cargo Ship) Final Report, Korea Maritime Equipment Institute Journal 3, 2008

[6] Mooring Fitting SWL Standardization (Dry Cargo Ship) Summery, Korea Maritime Equipment Institute Journal 3, 2008

[7] "OCIMF", 1997, Mooring Equipment Guidelines, 2nd Edition• "ISO 3913", 1977, Shipbuilding - Welded Steel Bollards, 1ST Edition• "JIS F 2001", 1995, Bollards

[8] "KS V 4011", 2009, Closed chock seat

[9] IACS, 2004c, Shipboard fittings and supporting hull structures associated with towing and mooring on conventional vessels (IACS UR A2)

[10] Sim, In-H. ; Yoon, Jae-D. ; Choi, Hang-S. "An Analysis of the Hydroelastic Response of Large Floating Structures in Oblique Waves ", Journal of the Society of Naval Architects of Korea, Volume 36, Issue, August 1999, pp.83-92 